\title{
IPM Synchronous Machine Drive Response to Symmetrical and Asymmetrical Short Circuit Faults
}

\author{
Brian A. Welchko, Student Member, IEEE, Thomas M. Jahns, Fellow, IEEE, Wen L. Soong, Member, IEEE, and \\ James M. Nagashima, Member, IEEE
}

\begin{abstract}
A closed-form solution is presented for the steady-state response of interior permanent magnet (IPM) synchronous machines to symmetrical short circuits including the effects of $q$-axis magnetic saturation. Machine response to single-phase asymmetrical short circuits is also investigated. Experimental data are presented to verify predicted behavior for both types of short circuits. It is shown that single-phase asymmetrical short circuit faults produce more severe fault responses with high pulsating torque and a significant threat of rotor demagnetization. A control strategy that purposely transitions such faults into symmetrical three-phase short circuits can minimize the fault severity and associated demagnetization risks. Implications for the design of IPM machines with improved fault tolerance are discussed.
\end{abstract}

Index Terms-Interior permanent magnet synchronous machine, inverter shutdown, protection, short circuit fault, variable speed drive.

\section{INTRODUCTION}

$\mathbf{T}$ HE adoption of permanent magnet synchronous machines in applications such as electric propulsion has been hindered by concerns about the special risks posed by short circuit faults in these machines. Interior permanent magnet (IPM) synchronous machines, with magnets buried inside the rotor, offer some important opportunities for minimizing such risks by making degrees of design freedom available that do not exist in other types of PM machines. More specifically, the presence of reluctance torque attributed to the magnetic saliency of the IPM machine's rotor provides machine designers with freedom to adjust the relative contributions of the reluctanceand magnet-based torque components in a way that cannot be matched in conventional surface PM machines.

Short circuits represent the most serious class of faults in IPM machines. Early researchers developed computer methods to simulate unbalanced short circuit faults in classic wound-field synchronous machines [1], [2]. More recently, simulation studies have also been extended to various faults

Manuscript received March 18, 2002; revised May 16, 2002. This paper published with permission of the 9th European Conference on Power Electronics and Applications, EPE 2001 Conference, Graz, Austria, 27-29 August 2001. This work was supported by the General Motors Corporation.

B. A. Welchko and T. M. Jahns are with the Department of Electrical and Computer Engineering, University of Wisconsin-Madison, 53706, USA (e-mail: bwelchko@ieee.org; jahns@engr.wisc.edu).

W. L. Soong is with the Department of Electrical and Electronic Engineering, University of Adelaide, Adelaide, 5005, South Australia (e-mail: wlsoong @eleceng.adelaide.edu.au).

J. M. Nagashima is with General Motors Advanced Technology Center, Torrance, CA 90503 USA (e-mail: james.nagashima@gm.com).

Digital Object Identifier 10.1109/TEC.2003.811746 in a particular IPM machine [3]. Minimization of the severity of certain faults was investigated from the standpoint of the physical machine construction in [4]. The results of these preceding studies are generalized in this paper to illuminate the impact that the two major IPM machine design variables-rotor magnet flux linkage and the inductance saliency ratio-have on the machine's short circuit behavior in an effort to minimize these effects.

Two distinct types of short circuit faults are investigated in this paper: 1) a symmetrical three-phase fault; and 2) an asymmetrical single-phase fault. For the case of the symmetrical fault, closed-form equations are derived to describe the machine response. The effects of $q$-axis magnetic saturation are included in the IPM machine model, and its significance will be demonstrated for tested IPM machines. The asymmetrical single-phase fault is analyzed using dynamic simulation techniques, with experimental results presented to verify the simulations. Important insights are drawn from the investigation regarding the selection of IPM machine parameters that will reduce the severity of these short circuit faults.

\section{MACHINE MODEL}

A magnetically-salient rotor is one of the key identifying characteristics of an IPM machine. By designing the machine with elevated levels of $q$-axis magnetic permeance, high flux densities can be developed in the rotor iron along the $q$-axis flux paths (i.e., orthogonal to the $d$-axis magnet flux orientation). However, the $q$-axis inductance is typically susceptible to magnetic saturation at medium to high current levels.

The electrical differential equations for an IPM machine in the synchronously-rotating $d q$ reference frame (Fig. 1) [5], [6], modified to include magnetic saturation, are given by

$$
\begin{aligned}
& v_{q}^{e}=r_{s} i_{q}^{e}+L_{q}^{\prime} \frac{d i_{q}^{e}}{d t}+\omega_{e} L_{d} i_{d}^{e}+\omega_{e} \Psi_{\mathrm{mag}} \\
& v_{d}^{e}=r_{s} i_{d}^{e}+L_{d} \frac{d i_{d}^{e}}{d t}-\omega_{e} L_{q} i_{q}^{e}
\end{aligned}
$$

where $L_{q}$ is a function of the $q$-axis current and

$$
L_{q}^{\prime}=L_{q}+\frac{\partial L_{q}}{\partial i_{q}^{e}} i_{q}^{e}
$$

accounts for the change in magnetic stored energy in the $q$-axis due to saturation.

Equations (1) and (2) only include magnetic saturation effects along the $q$-axis since the large effective air gaps along the $d$-axis created by the magnet cavities result in a nearly constant 

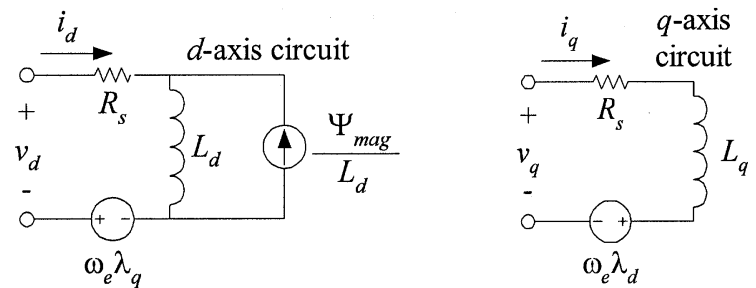

Fig. 1. IPM machine $d q$ equivalent circuits.

$d$-axis inductance that is independent of both the $d$ - and $q$-axis currents. Cross-saturation effects, manifested by current in one axis affecting the inductance of the other axis [7], are not included in this model since this paper focuses on multi-barrier IPM machines that have been shown to be relatively immune to this phenomenon [8].

To complete the modeling of the IPM machine, (4) gives the electromechanical torque produced by the machine

$$
T_{e m}=1.5 P\left[i_{q} \Psi_{\mathrm{mag}}+\left(L_{d}-L_{q}\right) i_{q} i_{d}\right]
$$

where $P$ is the number of pole pairs and $\Psi_{\text {mag }}$ is the permanent magnet flux linkage.

The $q$-axis inductance can typically be modeled quite accurately in a piecewise fashion using a power series as follows:

$$
\begin{aligned}
& L_{q}=C_{1}\left|i_{q}^{e}\right|^{C_{2}} \text { for } L_{q} \leq L_{q \max } \\
& L_{q}=L_{q \max }, \text { otherwise }
\end{aligned}
$$

where $C_{1}$ and $C_{2}$ are constants that characterize the saturation characteristics of $L_{q}$, and $L_{q \text { max }}$ is the unsaturated value of $L_{q}$. The derivative term in (3) can now be evaluated as

$$
\frac{\partial L_{q}}{\partial i_{q}^{e}}= \begin{cases}C_{1} C_{2}\left|i_{q}^{e}\right|^{\left(C_{2}-1\right)} & L_{q} \leq L_{q \max } \\ 0, & \text { otherwise. }\end{cases}
$$

A power series was chosen to model the $q$-axis saturation instead of a more common spline-based approach for several reasons. At low values of $q$-axis current, the rotor barriers do not exhibit saturation so a constant $L_{q}$ is appropriate. When the rotor barriers begin to saturate at elevated $q$-axis current values, the $q$-axis inductance decreases asymptotically with current, and the power series of (5) matches the measured inductance characteristics of IPM machines quite well, as will be shown in Sections III-VI of this paper. Furthermore, (5) and (6) are smooth functions that are conveniently compatible with the numerical simulation techniques used in this investigation.

\section{Symmetrical SHORT CIRCUIT}

Fig. 2 shows a simplified circuit diagram of the IPM machine adjustable-speed drive. A symmetrical three-phase short circuit is applied to the machine if either the three upper switches ( $\mathrm{T} 1$, $\mathrm{T} 3, \mathrm{~T} 5)$ or the three lower switches (T4, T6, T2) are permanently closed. Such a fault can result from active gating of the inverter switches, caused either unintentionally by a serious controller error, or intentionally in response to some other detected fault condition. The IPM machine will also see a three-phase short circuit condition if the inverter dc bus is inadvertently shorted, allowing the six free-wheeling diodes to conduct the

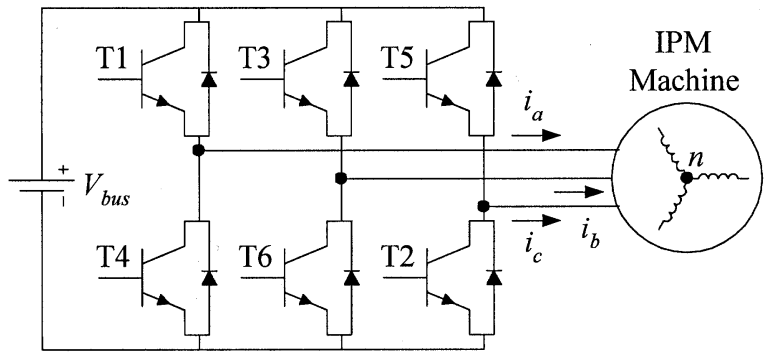

Fig. 2. Basic IPM machine drive configuration.

fault currents. Finally, physical damage to the cable connections between the electronic drive and the motor may cause a symmetrical three-phase short circuit fault.

Introducing zero values for $v_{q}$ and $v_{d}$ and setting the time derivatives in (1) and (2) to zero leads to expressions for the steady-state values of the currents during symmetrical short-circuit operation at a constant speed $\omega_{e}$. Solving for the steady-state currents and developed torque under these conditions yields

$$
\begin{aligned}
{\left[\begin{array}{c}
i_{d}^{e} s s \\
i_{q_{-}-s s}^{e}
\end{array}\right]=} & -\frac{1}{\omega_{e}^{2} L_{d} L_{q}+r_{s}^{2}}\left[\begin{array}{l}
\omega_{e}^{2} L_{q} \Psi_{\mathrm{mag}} \\
r_{s} \omega_{e} \Psi_{\mathrm{mag}}
\end{array}\right] \\
T_{e m_{-s s} s}= & \frac{3}{2} \operatorname{Pr}_{s} \Psi_{\mathrm{mag}}^{2} \\
& \times\left[\frac{-\omega_{e}}{\omega_{e}^{2} L_{d} L_{q}+r_{s}^{2}}+\left(L_{d}-L_{q}\right)\right. \\
& \left.\times \frac{\omega_{e}^{3} L_{q}}{\left(\omega_{e}^{2} L_{d} L_{q}+r_{s}^{2}\right)^{2}}\right] .
\end{aligned}
$$

The results of (7) and (8) are shown graphically in Figs. 3 and 4 for two actual IPM machines, one rated at $35 \mathrm{~kW}$ and the second at $70 \mathrm{~kW}$ (see Appendix for measured parameters). It should be noted that the motor speed curve is plotted using a logarithmic scale to highlight the curve shape at low speed. Separate curves are provided for the 70-kW machine with and without magnetic saturation to demonstrate its effect on shortcircuit performance. Saturation has only a minor effect on the stator current and torque curves for the $35-\mathrm{kW}$ machine, so only one curve for this machine is provided in each of these figures. In contrast, $q$-axis saturation in the $70-\mathrm{kW}$ machine depresses the peak torque by approximately $15 \%$.

These results include some interesting features. In particular, Fig. 4 shows that the short-circuit torque actually peaks at a very low speed corresponding to $\omega_{e}=r_{s} / \sqrt{L_{d} L_{q}}$. The negative $q$-axis current reaches its maximum at this same speed. This speed is approximately $100 \mathrm{r} / \mathrm{min}$ for the $70-\mathrm{kW}$ machine and $250 \mathrm{r} / \mathrm{min}$ for the $35-\mathrm{kW}$ machine. Both the $q$-axis current amplitude and torque drop very significantly at higher speeds. In contrast, the amplitude of the negative $d$-axis current (and the total stator current) monotonically increases with speed, asymptoting to a value of $-\Psi_{\mathrm{mag}} / L_{d}$ at high speeds.

The IPM machine is actually responding to the symmetrical short circuit as a special type of inside-out induction machine with the shorted stator windings playing the role of the rotor windings in a conventional induction machine. Extending this analogy, the permanent magnets serve as static excitation in the 


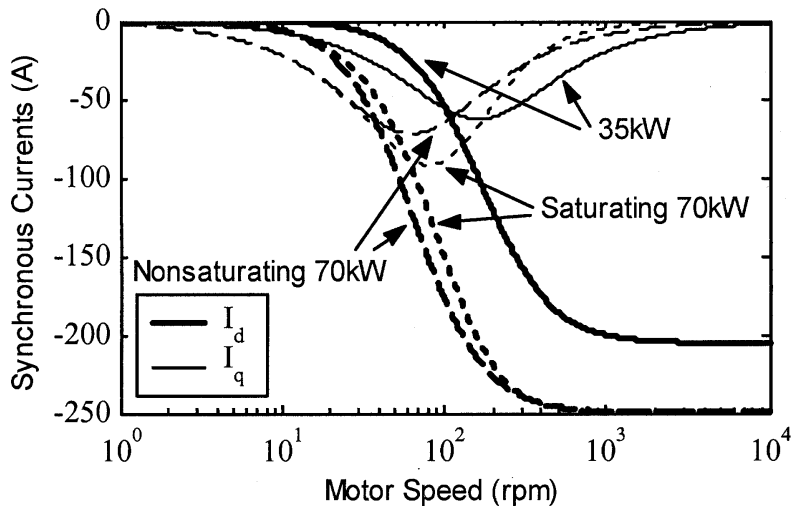

Fig. 3. Steady-state synchronous frame short-circuit currents for the $35-\mathrm{kW}$ machine and $70-\mathrm{kW}$ machine.

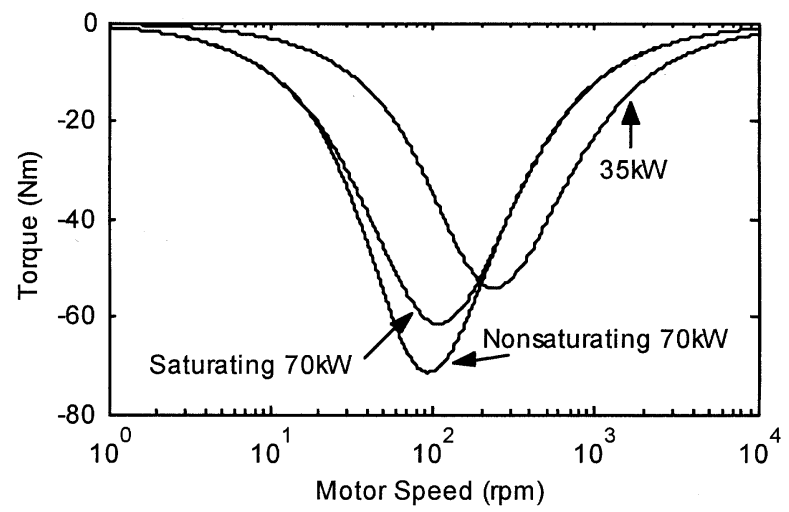

Fig. 4. Steady state short circuit motor torque for the $35-\mathrm{kW}$ machine and $70-\mathrm{kW}$ machine showing effects of $q$-axis saturation.

rotor reference frame so that the machine's steady-state torque-speed curve looks much like that of a conventional induction motor with zero-frequency stator excitation (i.e., dc braking). The well-known shape of the induction machine's steady-state torque-speed curve emerges more clearly if Fig. 4 is replotted against a linear rather than logarithmic speed axis.

It should be noted that the short circuit torque amplitude is proportional to the square of the magnet flux linkage as indicated by (8). Since the total machine torque is made up of the sum of a magnet torque and a reluctance torque component as indicated by (4), designing the IPM machine with a larger fraction of reluctance torque serves to minimize the magnet flux linkage and the resulting short circuit current and torque. It can be noted in Fig. 4 that the two machines develop nearly the same short circuit torque even though their power ratings differ by a factor of two. This is caused by the fact that the magnet flux linkage of the $35-\mathrm{kW}$ machine approaches the value for the 70-kW machine (see Appendix).

The dynamic simulation results presented in Figs. 5 and 6 for the $35-\mathrm{kW}$ machine indicate that the transients following application of a sudden short circuit are of short duration. For both machines, these transients are completed within $50 \mathrm{mS}$ of the fault initiation. The peak torque reached by the $35-\mathrm{kW}$ machine during the transient is significant but not dangerously high, reaching a value approximately $50 \%$ higher than its rated value of $96 \mathrm{Nm}$. Dynamic simulation results (not shown) for the $70-\mathrm{kW}$ machine exhibit similar transient behavior to that

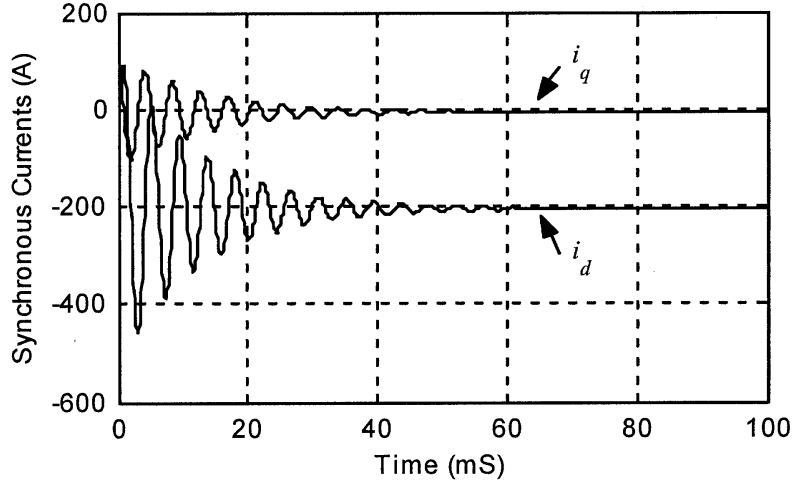

Fig. 5. Synchronous frame currents following a three-phase short circuit for the $35-\mathrm{kW}$ machine operating at $35 \mathrm{~kW}$ and $3500 \mathrm{r} / \mathrm{min}$ (constant).

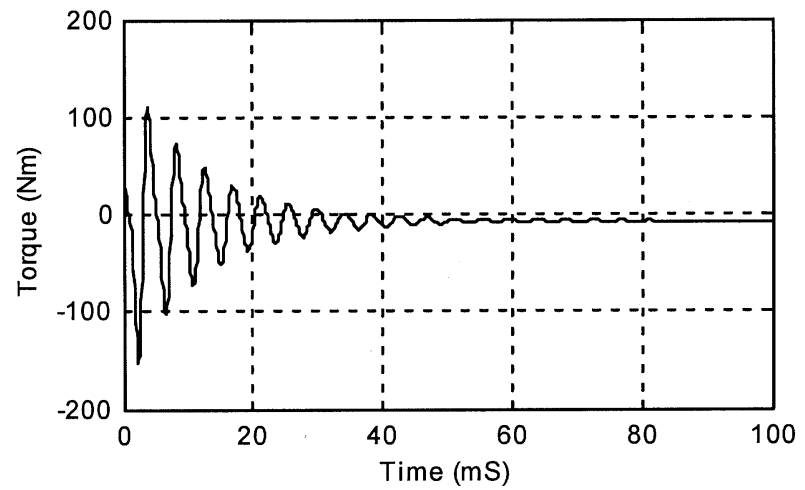

Fig. 6. Torque following application of a three-phase short circuit for the $35-\mathrm{kW}$ machine operating at $35 \mathrm{~kW}$ and $3500 \mathrm{r} / \mathrm{min}$ (constant).

demonstrated in Figs. 5 and 6. Since this three-phase short circuit is a symmetrically balanced fault, the $d$ - and $q$-axis fault response is independent of the initial rotor position.

The Fig. 5 curves suggest that the rotor magnets may be at some risk of demagnetization during the initial fault transient since the peak amplitude of the negative $d$-axis current reaches approximately twice the value of $\Psi_{\mathrm{mag}} / L_{d}$. (Note that $-\Psi_{\text {mag }} / L_{d}$ is the value of $i_{d}$ at which the total $d$-axis flux linkage reaches zero). The overshoot of the $d$-axis current is largest at high speeds where the amplitude of the $q$-axis current is reduced. As a result, the high-speed regime presents the highest risks of demagnetization for this short-circuit condition. However, it should be emphasized that demagnetization is ultimately a local phenomenon, and the actual threshold conditions for bulk demagnetization depend on the IPM machine design details [8].

\section{ASYMMETRICAL SHORT CIRCUIT}

The failure of a single inverter switch in a closed position results in an asymmetrical single-phase short circuit fault at the terminals of the IPM machine. For this investigation, it was assumed that switch T4 (Fig. 2) in phase $a$ is the failed switch. It is assumed that inverter protection circuitry immediately responds to open the complementary phase-leg switch (T1) to avoid a dangerous shoot-through inverter failure. One possible fault protection strategy is to immediately remove the gate pulses from all of the unfaulted switches. This results in 
the two unfaulted phases being connected to the dc link via their antiparallel diodes, with the faulted phase being directly connected to one of the link rails via the shorted switch. This condition corresponds to a special form of what has been referred to as uncontrolled generating mode (UCG) operation [9], [10].

Unlike the symmetrical three-phase short circuit condition discussed before, the single failed switch condition does not lend itself to a closed-form solution because of the rotational asymmetry manifested on both the stator and rotor elements. Results from a dynamic fault simulation for this fault response strategy are shown in Figs. 7 and 8 for the 35-kW machine operating at its maximum operating speed of $8000 \mathrm{r} / \mathrm{min}$. This corresponds to worst-case conditions since the machine back-emf voltage exceeds the bus voltage by the largest amount at maximum speed. The resulting fault currents and torque waveforms have large amplitudes, settling to their new steady-state values after only $6 \mathrm{mS}$ following application of the fault. The lower antiparallel diodes in the two adjacent phases provide the circuit paths for phase-to-phase short circuit currents to flow, with the internal machine back-emf voltages acting as the excitation sources.

The polarity of the resulting phase $a$ machine fault current is predominantly negative due to the presence of the anti-parallel diodes. Assuming that the machine neutral is floating, the sum of the phase currents in phases $b$ and $c$ must be correspondingly positive to balance the negative phase $a$ fault current. The Fig. 7 current waveforms show that nearly the entire fault current in phases $b$ and $c$ is positive, reflecting conduction through the lower antiparallel diodes in these two phases. However, the phase $b$ fault current exhibits periodic negative values, indicating that the back-emf voltage between phases $b$ and $a$ is sufficiently large at high speeds to force the upper phase $b$ antiparallel diode into conduction for brief intervals each cycle. Energy is returned to the dc link from the machine only during these intervals, resulting in a low average braking power. Fig. 8 shows that the braking torque is highly oscillatory, but its average value is less than $25 \%$ of the machine's steady-state torque rating, and the peaks are within the peak transient torque rating of the machine $(232 \mathrm{Nm})$.

The predominant frequency components that appear in the Fig. 7 current waveforms are dc and the second harmonic in addition to the fundamental. These current harmonics interact with the spinning rotor to create the Fig. 8 torque waveform that is actually dominated by the fundamental frequency component because of the interaction between the large stator dc component and the rotor magnets. However, it should be pointed out that the effects of magnetic saturation are significant for this fault due to the very high current values. Overall, saturation is very useful in this fault scenario since it serves to reduce the amplitudes of the resulting fault currents and torque.

The peak amplitude of the negative $d$-axis current predicted by this simulation is much higher than the value of $\Psi_{\mathrm{mag}} / L_{d}(=$ $205 \mathrm{~A}$ ) for the 35-kW IPM machine. As a result, the threat of demagnetization of the rotor magnets under such conditions becomes a serious consideration. The amplitude of the fault currents are determined by the back-emf voltage divided by the

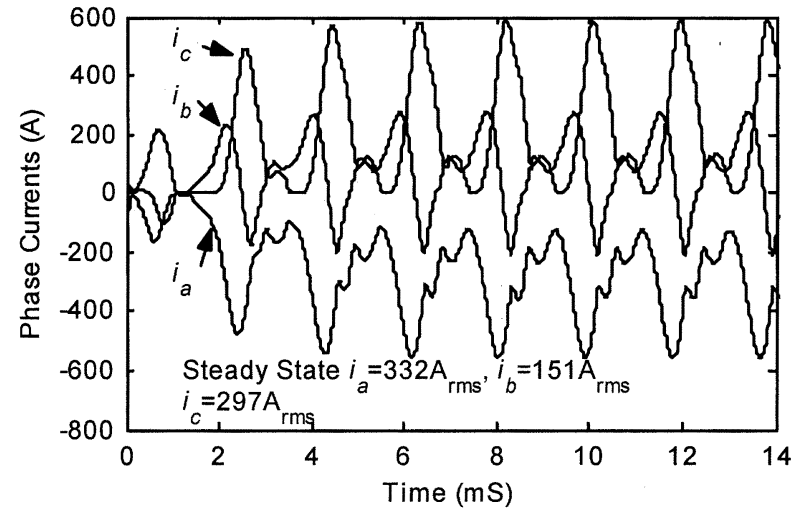

Fig. 7. Stator currents following a single-phase short circuit for the $35-\mathrm{kW}$ machine operating at $8000 \mathrm{r} / \mathrm{min}$ (constant) with $V_{\text {bus }}=350 \mathrm{~V}$.

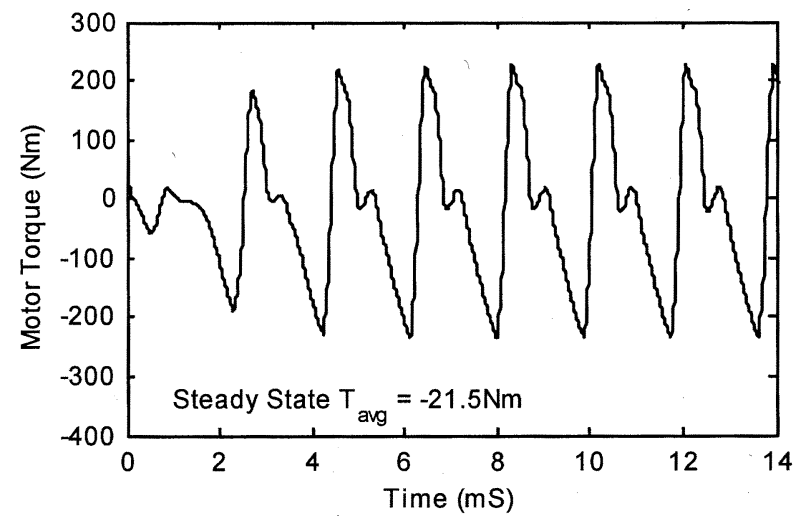

Fig. 8. Motor torque following a single-phase short circuit for the $35-\mathrm{kW}$ machine operating at $8000 \mathrm{r} / \mathrm{min}$ (constant) with $V_{\text {bus }}=350 \mathrm{~V}$.

machine reactance, aggravated for this fault condition by the dc components associated with the diode action. Since both the back-emf and reactance values are proportional to frequency, the fault current and torque amplitudes change little over wide ranges of rotor speed. It is only at low speeds that the current and torque amplitudes drop when the resistive effects of the machine become dominant.

Rather than removing the gating from the two unfaulted phases, another possible controller response is to close the remaining upper or lower switches from the other two phases, creating a symmetrical three-phase short circuit as discussed in the previous section of this paper. Although it may seem counterintuitive, the results of this investigation suggest that purposely transitioning to a symmetrical three-phase short will reduce both the risk of demagnetization and the braking torque compared to the asymmetrical single-phase fault. Simulation results demonstrating the improvement achieved by using this control action are shown in Figs. 9 and 10. Figs. 9 and 10 show the system reaching steady state with the single-phase short (gating signals removed from unfaulted switches) before the three-phase short is initiated. A properly designed controller could detect the shorted switch and command a three-phase short via the inverter before dangerous demagnetizing current amplitudes can develop. 


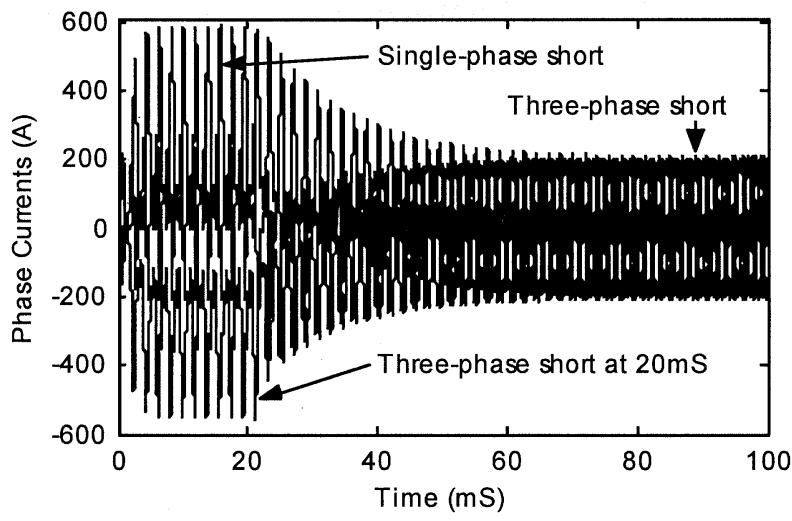

Fig. 9. Stator currents during a transition from a single-phase short at $t=0$ to a three-phase short at $t=20 \mathrm{mS}$ for $8000 \mathrm{r} / \mathrm{min}$ (constant).

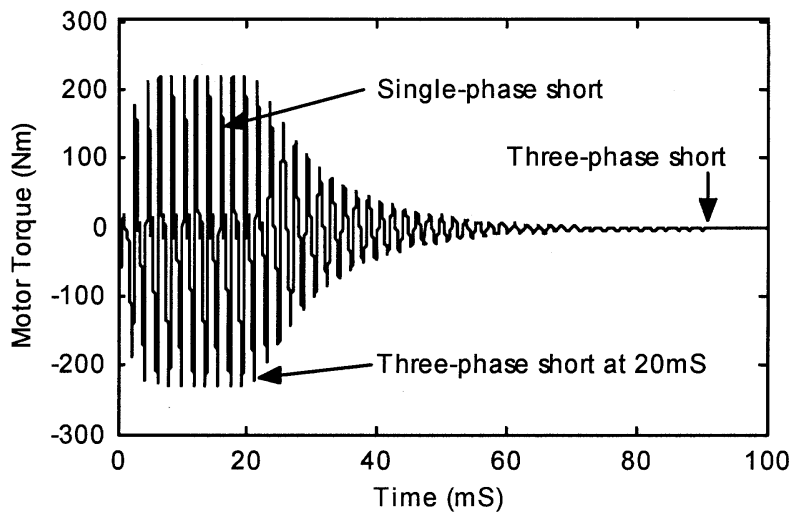

Fig. 10. Motor torque during a transition from a single-phase short at $t=0$ to a three-phase short at $t=20 \mathrm{mS}$. Speed $=8000 \mathrm{r} / \mathrm{min}$ (constant).

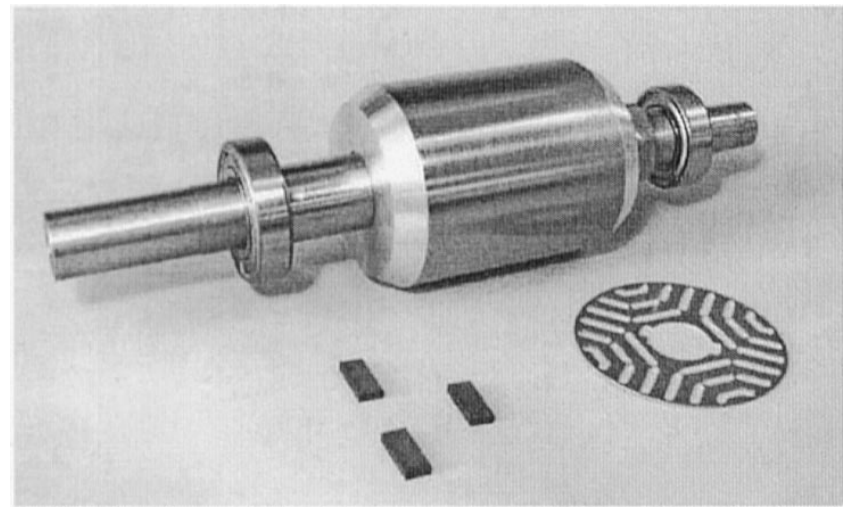

Fig. 11. 2.2-kW three-barrier interior PM rotor with lamination and ferrite magnet samples.

\section{EXPERIMENTAL RESULTS}

Laboratory tests were carried out to verify the predicted short circuit fault characteristics developed in the preceding sections. Unfortunately, the two IPM machines studied in the preceding sections were unavailable for testing, so another IPM machine [11] was used to develop this comparison. The $2.2-\mathrm{kW}$ experimental machine uses a commercially available four-pole, $50-\mathrm{Hz}$ induction motor stator. The rotor (Fig. 11) incorporates a threebarrier design using ferrite block magnets (eight magnets per pole) and is $93 \mathrm{~mm}$ in diameter.

The measured inductance data are shown in Fig. 12. This data were obtained (in the second quadrant) by injecting increasing

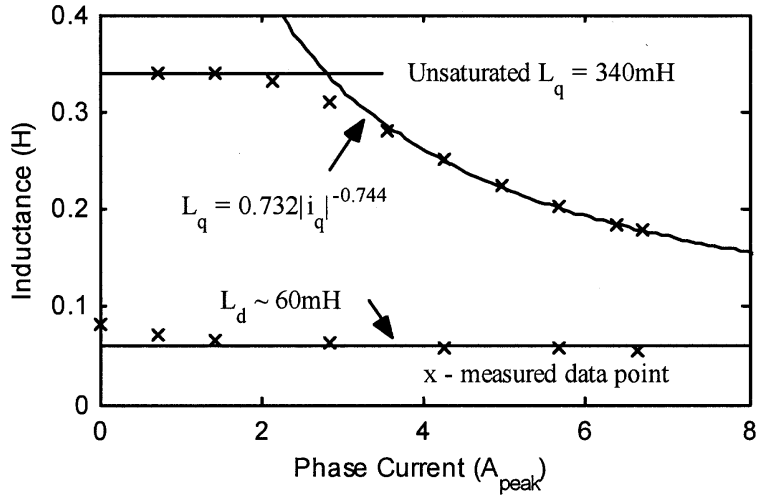

Fig. 12. Measured inductance data

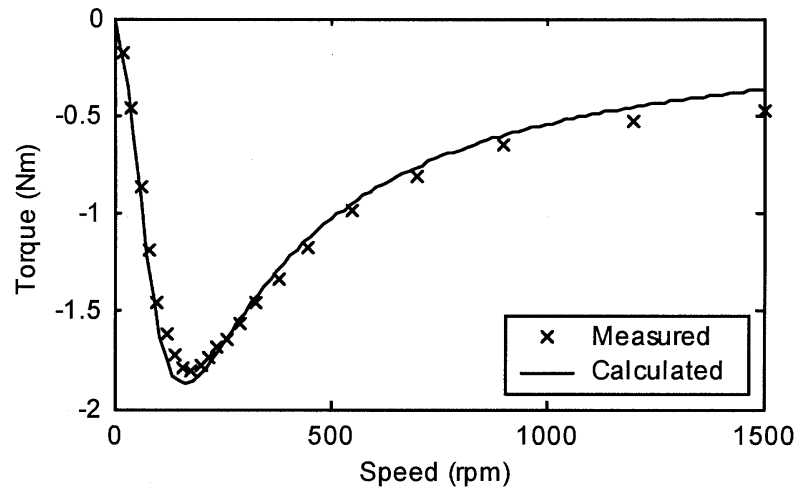

Fig. 13. Measured and calculated steady-state motor torque for a symmetrical three-phase short circuit fault.

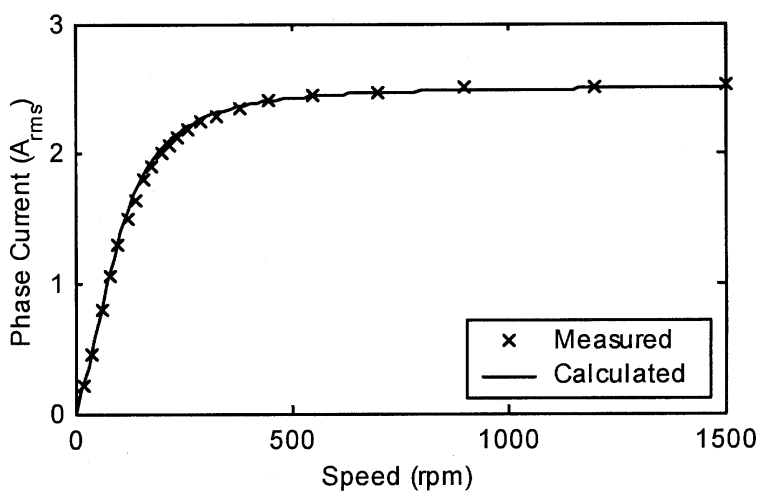

Fig. 14. Measured and calculated steady-state phase current for a symmetrical three-phase short circuit fault.

values of current in one axis while holding the other axis current to zero. No evidence of significant cross-saturation effects have been apparent in this machine. As seen in the figure, $q$-axis saturation of $L_{q}$ can be modeled accurately using a power series, with only a slight deviation at the onset of saturation. Even though the measured $L_{d}$ characteristic exhibits slight saturation characteristics, a constant value of $60 \mathrm{mH}$ was chosen for modeling purposes. Since the machine torque is influenced by the difference between $L_{q}$ and $L_{d}$, and $L_{q}$ generally exceeds $L_{d}$ by a large margin, saturation of $L_{d}$ can generally be neglected for most IPM machines as long as the $L_{q}$ saturation effects are properly captured.

Figs. 13 and 14 show the measured steady-state torque and stator current data for a symmetrical three-phase short circuit 


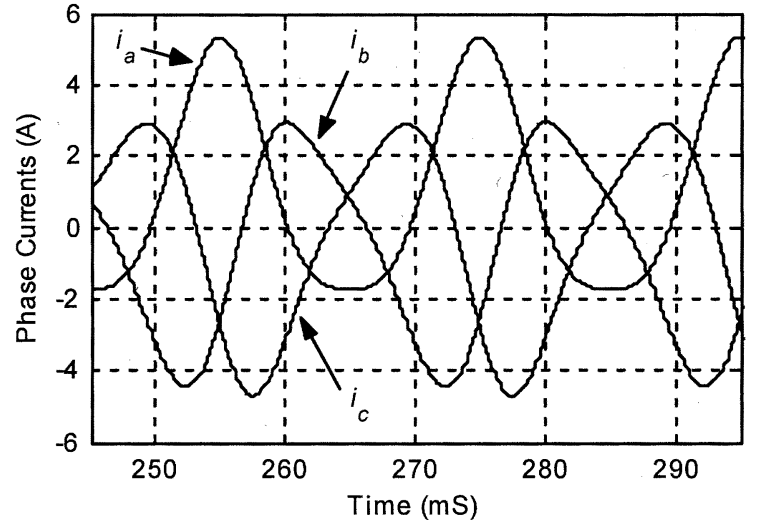

Fig. 15. Simulated single phase short circuit currents at $1500 \mathrm{r} / \mathrm{min}$ (constant) and $V_{\text {bus }}=10 \mathrm{~V}$. Phase $a$ shorted to positive dc bus.

overlaid with predicted results using (7) and (8). The agreement between predicted and measured results is excellent. The speed in both of these figures is plotted along the horizontal axis using a linear rather than a logarithmic scale, so the familiar shape of the induction machine torque curve is much more readily apparent than it was in Fig. 4.

Experimental tests for the asymmetrical single-phase short circuit fault were carried out with machine phase $a$ short-circuited to the positive dc bus. All of the other inverter switches were disabled, leaving only the anti-parallel diodes to conduct current except in the faulted switch. Due to the threat of rotor demagnetization, these tests were conducted with a reduced bus voltage $(10 \mathrm{~V})$ to protect the machine. Figs. 15 and 16 show the simulated and experimental results for the phase currents at $1500 \mathrm{r} / \mathrm{min}$ with excellent agreement in both waveshape and amplitude. Note that each of the phase current waveforms include intervals with both current polarities, indicating that intervals of power delivery back to the dc link are more extensive in this case than in Figs. 7 and 8 due to the very low bus voltage.

Figs. 17 and 18 show the faulted phase $a$ current along with the instantaneous torque at a lower rotor speed of $240 \mathrm{r} / \mathrm{min}$. This low speed was chosen to fall within the limited bandwidth capabilities of the torquemeter. Waveshape agreement is generally excellent for both the current and torque, and the measured torque amplitude is within $10 \%$ of the predicted value. The slight waveshape disagreement between the measured and simulated results can be attributed to the assumptions of a perfectly sinusoidal winding distribution and back emf in the simulations. Additional sources of these small discrepancies include the neglect of mechanical losses in the simulations and small errors in the estimation of the machine parameters. The sensitivity of the calculated torque to parameter errors is particularly high at this speed which was specifically selected to fall near the peak of the steady-state three-phase short-circuit torque curve.

\section{DESIGN CONSIDERATIONS}

The designer of an IPM machine has the freedom to adjust the relative contributions of the rotor permanent magnets and the rotor magnetic saliency to the machine's torque production. This design flexibility can be utilized to achieve a variety of objectives, such as providing wide speed ranges of constant power operation [12]. However, it is also desirable to understand how

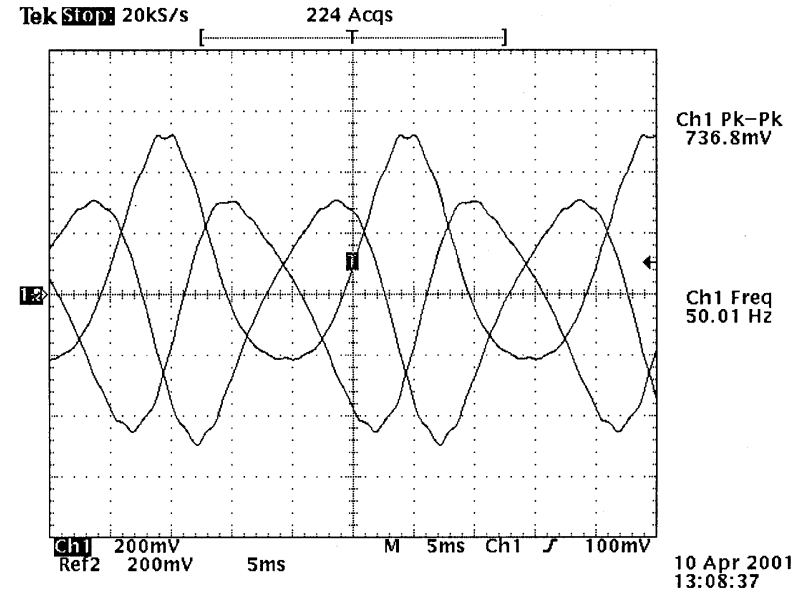

Fig. 16. Experimental single phase short circuit currents at $1500 \mathrm{r} / \mathrm{min}$ and $V_{\text {bus }}=10 \mathrm{~V}$. Phase $a$ shorted to positive dc bus. $2 \mathrm{~A} /$ div.

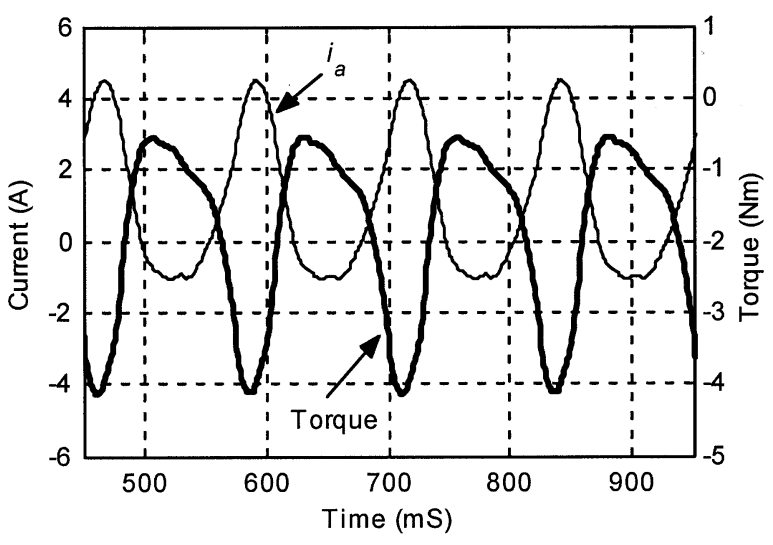

Fig. 17. Simulated single phase short circuit at $240 \mathrm{r} / \mathrm{min}$ (constant) and $V_{\text {bus }}=10 \mathrm{~V}$. Phase $a$ shorted to positive dc bus.

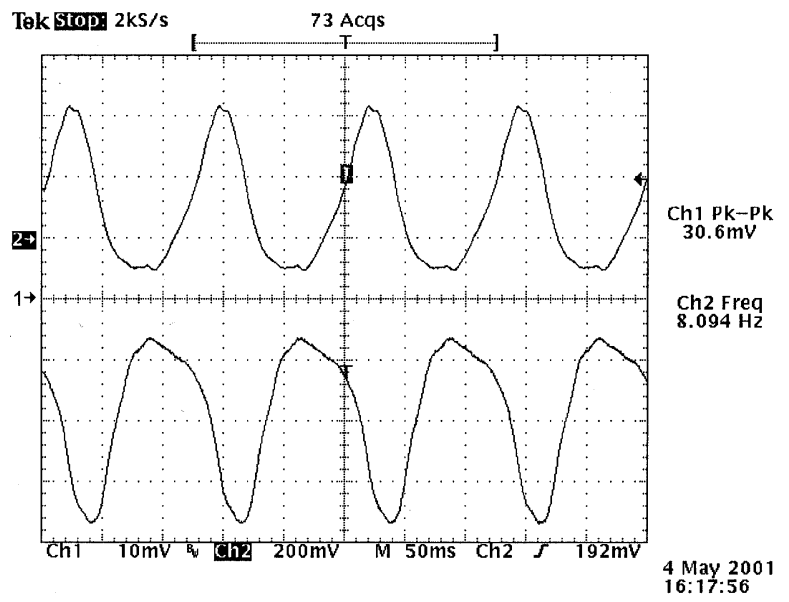

Fig. 18. Experimental single phase short circuit at $240 \mathrm{r} / \mathrm{min}$ and $V_{\text {bus }}=$ $10 \mathrm{~V}$. Top signal is $i_{a}: 2 \mathrm{~A} /$ div. Lower signal is instantaneous torque: $1 \mathrm{Nm} /$ div.

the IPM design choices influence its short circuit fault characteristics, particularly when the application calls for the minimization of these effects.

The design space for IPM machines can be conveniently represented by two principal rotor design parameters: the magnet flux linkage $\Psi_{\text {mag }}$, and the rotor saliency ratio $L_{q} / L_{d}$. These 


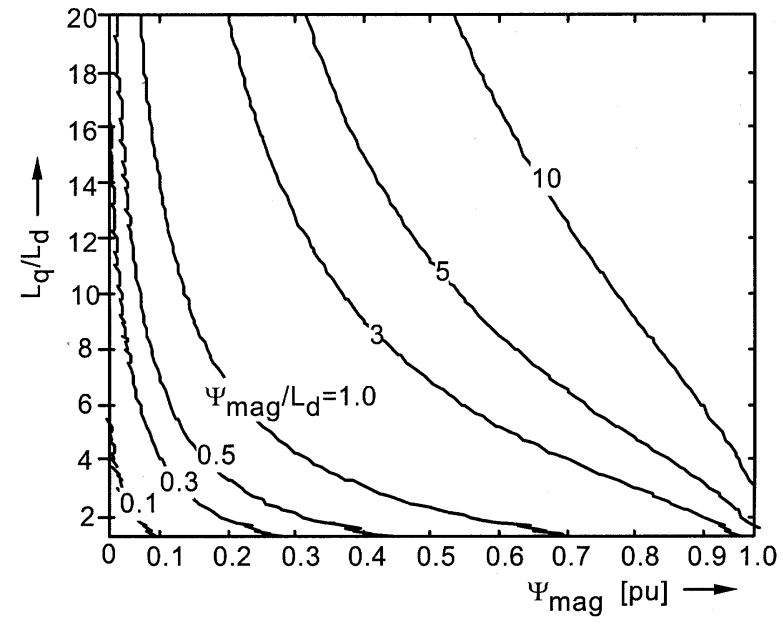

Fig. 19. Contour plot of maximum steady-state three-phase short circuit current $\left(=\Psi_{\mathrm{mag}} / L_{d}\right)$ in per unit as a function of IPM machine design parameters.

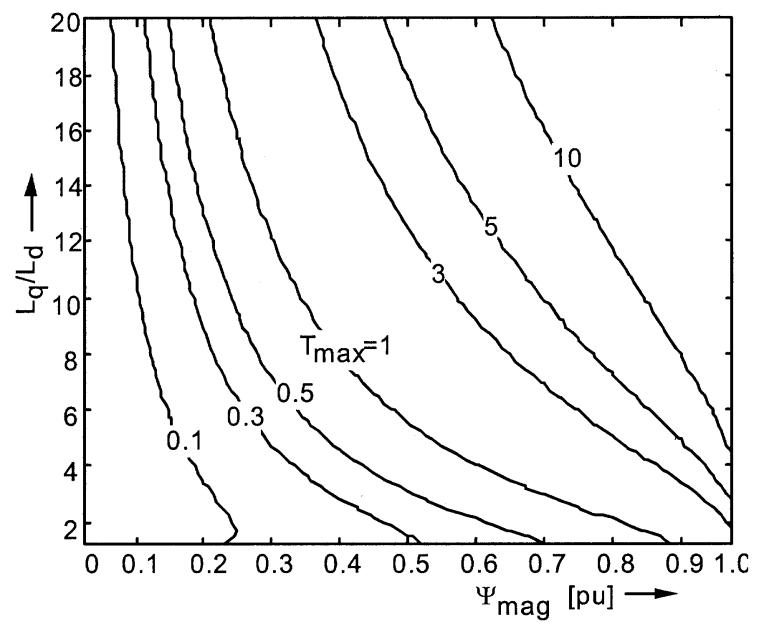

Fig. 20. Contour plot of maximum average steady-state three-phase short circuit torque in per unit as a function of IPM machine design parameters.

parameters become particularly useful for providing broad insights into IPM design trade-offs when the machine variables are normalized using a per-unit system based on the machine ratings [13]. For example, Fig. 19 shows a contour plot for the maximum value of steady-state three-phase short circuit current $\left(=\Psi_{\mathrm{mag}} / L_{d}\right)$ in the two-dimensional (2-D) IPM design space formed by $\Psi_{\text {mag }}$ and $L_{q} / L_{d}$. This plot shows that the peak short circuit current increases monotonically with both $\Psi_{\text {mag }}$ and $L_{q} / L_{d}$, although these curves cannot be considered exact since magnetic saturation effects are not included. Interestingly, the contour associated with $\Psi_{\mathrm{mag}} / L_{d}=1$ corresponds exactly to the locus of IPM machine designs with the widest possible speed range of constant power operation [12]. Any machine designs lying to the right of this contour must tolerate short circuit currents at high speed that exceed the machine's rated current.

Fig. 20 shows that similar trends apply to the peak average three-phase short circuit torque (steady-state) that occurs at low speeds, with torque increasing as either $\Psi_{\text {mag }}$ or $L_{q} / L_{d}$ increases. Evaluation of this maximum torque using (8) indicates that it is insensitive to the stator resistance $r_{s}$, consistent with the maximum torque in an induction machine that does not depend on the rotor resistance. Inspection of these curves indicates that
IPM machines designed for wide ranges of constant power operation (i.e., along the contour $\Psi_{\mathrm{mag}} / L_{d}=1$ defined in Fig. 19) will have peak steady-state short circuit torque values of 0.5 p.u. or less, with the exact value depending on the combination of $\Psi_{\text {mag }}$ and $L_{q} / L_{d}$ values. These contour plots suggest that designing machines with high values of $\Psi_{\mathrm{mag}} / L_{d}$ exceeding 1 p.u. (i.e., rated current) should generally be avoided in order to minimize inverter switch and mechanical load stresses caused by the fault.

Dynamic simulations of both the three-phase and asymmetric single-phase fault were conducted for various machine design parameter combinations during both steady-state and transient fault initiation conditions. These results suggest that high values of rotor magnetic saliency (i.e., high $L_{q} / L_{d}$ values) tend to aggravate the demagnetization stresses by increasing the peak values of $-i_{d}$. However, demagnetization is ultimately a localized phenomenon depending on the MMF experienced by each segment of the rotor magnets, and further investigation is required to evaluate the true extent of these demagnetization effects.

\section{CONCLUSIONS}

This paper has investigated the short circuit characteristics of IPM synchronous machines under both three-phase symmetrical and single-phase asymmetrical fault conditions, including the effects of magnetic saturation. Both steady-state and transient fault initiation conditions have been considered. Key observations include the following.

- A three-phase symmetrical short circuit results in low steady-state torque at moderate to high speeds, peaking at low speeds where the stator resistance effects dominate.

- The steady-state three-phase short circuit current asymptotes to $\Psi_{\mathrm{mag}} / L_{d}$ at high speeds, suggesting that the machine should be designed with $\Psi_{\mathrm{mag}} / L_{d}<1$ pu in order to limit post-fault inverter stresses.

- The stresses associated with the asymmetric single-phase fault are noticeably worse than those for the three-phase fault, resulting in highly oscillatory torque and high peak currents, including significant demagnetization stresses.

- The seriousness of the single-phase fault emphasizes the importance to escaping this condition as soon as possible via protective control action that might include transition into the symmetrical three-phase short circuit condition if no other alternative exists for opening the faulted switch.

Experimental results have confirmed the key results of this investigation. Despite this progress, significant work remains to identify the most effective approaches for minimizing the negative effects of short circuit faults on IPM machines in various applications without degrading their desirable performance characteristics during normal operation.

\section{APPENDIX}

\section{A. Interior Permanent Magnet Machine Parameters}

Machine 1: three phase, $35 \mathrm{~kW}$ peak, $96 \mathrm{Nm}, 270 \mathrm{~V}$, eight pole, $3500 \mathrm{r} / \mathrm{min}$ with

$$
\begin{aligned}
r_{s} & \approx 0.04 \Omega \quad \Psi_{\text {mag }} \approx 0.072 \mathrm{~Wb} \quad L_{d} \approx 0.35 \mathrm{mH} \\
L_{q \max } & \approx 0.94 \mathrm{mH} \quad C_{1} \approx 0.0165 \mathrm{H} / \mathrm{A} \quad C_{2} \approx-0.63
\end{aligned}
$$


Machine 2: three phase, $70 \mathrm{~kW}$ peak, $139 \mathrm{Nm}, 270 \mathrm{~V}$, six pole, $4800 \mathrm{r} / \mathrm{min}$ with

$$
\begin{aligned}
r_{s} \approx 0.014 \Omega \quad \Psi_{\operatorname{mag}} \approx 0.10 \mathrm{~Wb} \quad L_{d} \approx 0.4 \mathrm{mH} \\
L_{q \max } \approx 1.2 \mathrm{mH} \quad C_{1} \approx 0.0043 \mathrm{H} / \mathrm{A} \quad C_{2} \approx-0.39
\end{aligned}
$$

Machine 3: three phase, $2.2 \mathrm{~kW}$ rated, $14 \mathrm{Nm}, 415 \mathrm{~V}$, four pole, $1500 \mathrm{r} / \mathrm{min}$ with

$$
\begin{aligned}
r_{s} & \approx 3.01 \Omega \quad \Psi_{\text {mag }} \approx 0.213 \mathrm{~Wb} \quad L_{d} \approx 60 \mathrm{mH} \\
L_{q \max } & \approx 340 \mathrm{mH} \quad C_{1} \approx 0.732 \mathrm{H} / \mathrm{A} \quad C_{2} \approx-0.744
\end{aligned}
$$

\section{ACKNOWLEDGMENT}

The authors would like to acknowledge the motivation provided by the Wisconsin Electric Machines and Power Electronics Consortium (WEMPEC) at the University of Wisconsin-Madison. The helpful advice of Prof. T. A. Lipo at the University of Wisconsin-Madison is gratefully acknowledged. This work made use of shared facilities supported by the National Science Center under Award EEC-9731677.

\section{REFERENCES}

[1] H. H. Hwang, "Transient analysis of unbalanced short circuit of synchronous machines," IEEE Trans. Power Apparat., vol. PAS-88, pp. 67-72, Jan. 1969

[2] G. Reddy and C. V. Jones, "Line-line short circuit of synchronous machine: Illustration of computer-aided machine analysis," Proc. Inst. Elect. Eng., vol. 118, pp. 161-168, Jan. 1971.

[3] N. Bianchi, S. Bolognani, and M. Zigliotto, "Analysis of PM synchronous motor drive failures during flux weakening operation," in Proc. Conf. Rec. Power Electron. Specialists Conf., vol. 2, 1996, pp. $1542-1548$.

[4] A. G. Jack, B. C. Mecrow, and J. A. Haylock, "A comparative study of permanent magnet and switched reluctance motors for high-performance fault-tolerant applications," IEEE Trans. Ind. Applicat., vol. 32, pp. 889-895, July/Aug. 1996.

[5] W. Soong, "Design and Modeling of Axially-Laminated Interior Permanent Magnet Motor Drives for Field-Weakening Applications," Ph.D., Dept. Electron. Elect. Eng., Univ. Glasgow, Glasgow, U.K, 1993.

[6] T. M. Jahns, G. B. Kliman, and T. W. Neumann, "Interior PM synchronous motors for adjustable speed drives," IEEE Trans. Ind. Applicat., vol. IA-22, pp. 738-747, July/Aug. 1986.

[7] A. Vagati, M. Pastorelli, and G. Franceschilini, "Effect of cross-coupling in synchronous reluctance motors," in Proc. Intell. Motion, 1997, pp. 279-285.

[8] E. C. Lovelace, "Optimization of a Magnetically Saturable Interior Permanent-Magnet Synchronous Machine Drive," Ph.D., Dept. Elect. Eng. And Comput. Sci., Massachusetts Institute of Technology, Cambridge, MA, USA, 2000.

[9] T. M. Jahns and V. Caliskan, "Uncontrolled generator operation of interior PM synchronous machines following high speed inverter shutdown," IEEE Trans. Ind. Applicat., vol. 35, no. 6, pp. 1347-1357, Nov./Dec. 1999.

[10] B. A. Welchko, T. M. Jahns, and S. Hiti, "IPM synchronous machine drive response to a single-phase open circuit fault," IEEE Trans. Power Electron., vol. 17, pp. 764-771, Sept. 2002.

[11] W. L. Soong, N. Ertugrul, E. C. Lovelace, and T. M. Jahns, "Investigation of interior permanent magnet offset-coupled automotive integrated starter/alternator," in Proc. Conf. Rec. IEEE IAS Annu. Meeting, vol. 1, 2001, pp. 429-436.

[12] W. Soong and T. J. E. Miller, "Field-Weakening performance of brushless synchronous AC motor drives," Proc. Inst. Elect. Eng.- Electr. Power Applicat., vol. 141, no. 6, pp. 331-339, 1994.

[13] A. K. Adnanes, "Torque analysis of permanent magnet synchronous motors," in Proc. IEEE Power Electron. Specialists Conf., 1991, pp. 695-701.

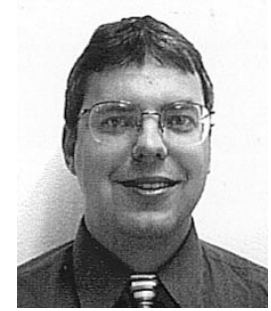

Brian A. Welchko (S'98) received the B.S. and M.S. degrees in electrical engineering from Ohio University, Athens, in 1994 and 1996, respectively. He is currently pursuing the $\mathrm{Ph} . \mathrm{D}$. degree at the University of Wisconsin-Madison (UW).

While at UW, he worked summers with the Otis Elevator Corporation, Farmington, CT, and also at General Motors Advanced Technology Center, Torrance, CA. His research interests are in the control of induction and interior permanent magnet synchronous machines.

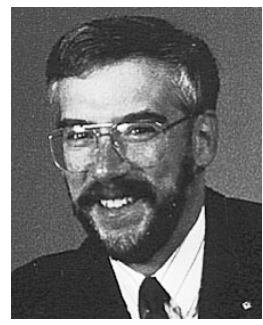

Thomas M. Jahns (S'73-M'79-SM'91-F'93) received the S.B., S.M., and Ph.D. degrees in electrical engineering in 1974 and 1978 from Massachusetts Institute of Technology, Cambridge.

$\mathrm{He}$ joined the faculty of the University of Wisconsin-Madison in 1998 as a Professor in the Department of Electrical and Computer Engineering, where he is also an Associate Director of the Wisconsin Electric Machines and Power Electronics Consortium (WEMPEC). Prior to coming to UW-Madison, he was with GE Corporate Research and Development, Schenectady, NY, for 15 years, where he pursued new power electronics and motor drive technology in a variety of research and management positions. His research interests include permanent magnet synchronous machines for a variety of applications ranging from high-performance machine tools to low-cost appliance drives. During 1996-1998, he conducted a research sabbatical at the Massachusetts Institute of Technology, where he directed research activities in the area of advanced automotive electrical systems and accessories as co-director of an industry-sponsored automotive consortium.

Dr. Jahns received the William E. Newell Award by the IEEE Power Electronics Society (PELS) in 1999. He has been recognized as a Distinguished Lecturer by the IEEE Industry Applications Society (IAS) during 1994-1995 and by IEEE-PELS during 1998-1999. He has served as President of PELS (1995-1996) and as a member of the IAS Executive Board from 1992 to 2001.

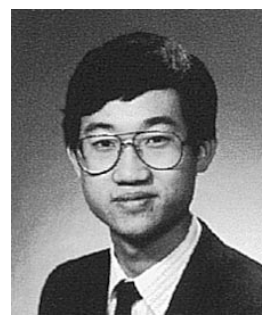

Wen L. Soong (M'93) was born in Kuala Lumpur, Malaysia, and received the B.Eng. degree from the University of Adelaide, Australia, in 1989, and the $\mathrm{Ph} . \mathrm{D}$. degree from the University of Glasgow, Scotland, U.K., in 1993.

He worked for four years as an electrical engineer in the Power Controls Program at General Electric Corporate Research and Development, Schenectady, NY, before taking up a teaching position in the Electrical and Electronic Engineering Department at the University of Adelaide, Australia. His current research interests include permanent magnet and reluctance motor drives, and motor condition monitoring. He has been granted nine U.S. patents.

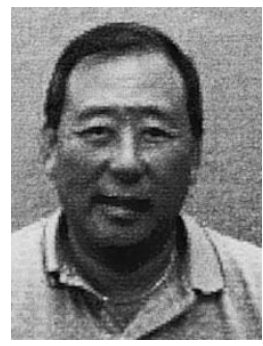

James M. Nagashima (M'97) was born in Chicago, IL, in 1946. He received the B.S. degree in electrical engineering from California State University, Long Beach, in 1969, and the Masters degree in Business Administration in 1983 from California Lutheran University, Thousand Oaks, CA.

Currently, he is the Manager of Advanced Development for General Motors Advanced Technology Center, Torrance, CA. He is responsible for developing new power electronics and motor drives for General Motors' electric, hybrid, and fuel cell vehicles. He was Power Systems Manager for Hughes Space and Communications Group, El Segundo, CA, Engineering Director for Rantec Power Systems Division of Emerson Electric, Engineering Director for Jeta Power Systems, and Engineering Manager for Power-One, Camarillo, CA.

Mr. Nagashima represents General Motors on many academic and government committees and is a member of SAE. 